\title{
Preliminares hacia una recuperación del cuerpo en el pensamiento
}

\section{latinoamericano contemporáneo}

Horacio Cerutti Guldberg

CCYDEL, UNAM

RESUMEN: El cuerpo ha sido el lugar tradicionalmente excluido en el pensamiento ilustrado. El autor plantea las estrategias en las que el pensamiento latinoamericano lo ba recuperado.

ABSTRACT: Traditionally, the body has been excluded in the Ilustrated thought. The author poses that Latin American thought has recover the body through various strategies.

\section{Para Tutis}

El presente trabajo tiene pretensiones muy (de)limitadas. Se trata de aproximarse de manera apenas provisional e hipotética a algunas, sólo algunas, de las modalidades que ha adoptado el pensamiento latinoamericano para reapropiarse de los propios cuerpos que nos constituyen. Por supuesto, asumo los riesgos evidentes y premeditados de hasta forzar en algunos casos los enfoques a fin de llevar agua para este molino... No me arrepiento. La demanda de reconocernos como corporales es urgente y más que secular. 


\section{A) Opción por los cuerpos...}

"Cuando iba al templo, éste se hacía pequeño para su cuerpo. No quiero decir con esto que nuestro templo sea en realidad pequeño, ni que la hermosura de Thamar sea tan abundante que llame locamente la atención, sino que el templo y Thamar no estaban precisamente de acuerdo"'.

La opción constituye un tópico de larga data en la reflexión contemporánea. En las modalidades que todavía adopta se remonta hasta el existencialismo francés, particularmente hasta Jean Paul Sartre. Pero, lo importante - con todo lo interesante que sería reexaminar esos antecedentes- es la renovada vigencia que adquirió en nuestra región geocultural a partir de finales de los sesenta o sea en la segunda mitad del siglo pasado. Particularmente en el pensamiento de la liberación y, sobre todo, en la reflexión teológica. Es conocida la expresión nuclear de la teología de la liberación: la "opción por los pobres". Importa destacar que esta opción, decisión, elección, toma de partido significaba inicialmente un colocarse del lado de los pobres, al precio de asumir todos los costos de tal actitud. También es sabido que la jerarquía eclesiástica católica más conservadora supo acotar la radicalidad de esta propuesta mediante el añadido de un terrmino que se ha conservado hasta hoy como ingrediente ya indispensable de esa expresión, al punto de casi confundirse con ella: opción "preferencial" por los pobres. Esa preferencia impidió no excluir de entrada a los que no eran pobres e, incluso, permite en casos extremos seguir militantemente del lado de los ricos y poderosos. Esto fue criticado oportunamente por Hugo Assman, quien advirtio, además, que por eso mismo el lenguaje no garantiza nada. Es posible darse muchos golpes de pecho y pronunciar palabras, pero si los hechos no acompañan al discurrir es poco lo que se puede esperar de las palabras solas ${ }^{2}$.

Con toda claridad anotaba la dificultad de este tópico en una vision retrospectiva Gustavo Gutiérrez y, por supuesto, en perspectiva teologica. "La palabra "opción" no siempre ha sido bien interpretada. Como toda expresión tiene sus límites, pero con ella se quiere acentuar el carácter libre y comprometedor de una decisión. No es algo facultativo, si entendemos por ello que un cristiano puede hacer o no dicha opción por los pobres, como tampoco es facultativo el amor que debemos a toda persona humana, sin excepción. Se trata de una solidaridad profunda y permanente, de una inserción cotidiana en el mundo del pobre. De otro lado, la palabra "opción" tampoco supone necesariamente que quienes la 
hacen no pertenecen al mundo de los pobres; así es en muchos casos, pero conviene precisar que los mismos pobres deben tomar también esta decisión" ". En estas palabras quedaban bien anudadas las dimensiones teológica y antropológica de esta expresión fundamental.

En un sentido muy semejante se expresaba Ignacio Ellacuría en la misma obra colectiva. "La opción preferencial por los pobres, entendida de modo radical y efectivo, de modo que éstos sean los que dinámicamente tomen la iniciativa, puede, ante todo, transformar la Iglesia radicalmente y puede así constituirse en clave y motor de lo que ha de ser una utopía cristiana como proyecto histórico liberador. Tal movimiento se refleja ya en las distintas formas teóricas y prácticas de la teología de la liberación, que es en sí misma un modo de profetismo eficaz para la animación de una nueva utopía histórica cristiana. Por ello se la teme tanto dentro y fuera de la Iglesia"4. No es ahora el momento de entrar a detallar la cuestión de la utopía, aunque conviene anotar que se encuentra unida muy estrechamente a la cuestión de la opción. Tanto en el pensamiento cristiano como en cualquier enfoque secular que se adopte ${ }^{5}$.

La cuestión de la opción no es asunto menor, porque alude de modo central al ejercicio mismo de la libertad. Para que haya verdadera opción o elección o decisión responsable es menester contar con alternativas. Dos al menos. Por ello, el uso de la expresión está permanentemente amenazado, como se puede constatar ad nauseam en los propios textos. No es raro encontrar formulaciones como la siguiente: no queda más opción que... Lo cual pone en cuestión la posibilidad misma de la opción, en la medida en que aparece como una decisión forzada o inapelable. Desde el punto de vista teológico, el asunto tiene su fundamento, porque como dice Gutiérrez no es cuestión "facultativa", en la medida en que Dios mismo ha establecido el mandato. Se es libre de aceptarlo o no. Pero, en caso de rechazarlo, mal se puede seguir identificándose como cristiano.

En todo caso, en las filosofías para la liberación se debatió el asunto, aunque las ambigüedades no fueron del todo superadas. El caso más significativo, quizá, es el de la propuesta de una opción restringida a los sectores medios, también denominados clases medias o pequeña burguesía, según los casos, como único segmento social en capacidad de optar. Dado que al no ser ricos ni pobres son los únicos en condiciones de decidir responsablemente de qué lado ubicarse ${ }^{6}$. Por supuesto, una perspectiva como ésa aparecería claramente cuestionada e impugnada por posiciones como la antes mencionada de Gustavo Gutiérrez.

Prelimincrea haclo una recuperación del cuepo en el peneamiento latinocrnericano contemporíneo 
En un estudio reciente, Héctor Samour examina con todo cuidado la filosofía de Ignacio Ellacuría y reconstruye el hilo genético de su gestación. Su trabajo tiene entre otros méritos el de señalar cómo el teólogo y filósofo jesuita vasco salvadoreño elaboró conceptualmente la cuestión de la opción. A punto que el texto se cierra con estas sugerentes palabras: “... Ellacuría optó por vivir en el mundo de los desposeídos y los crucificados de la tierra, se ubicó conscientemente en el lugar de la realidad histórica donde no había posibilitación sino opresión, que es lugar de las víctimas despojadas de toda figura humana, y por él dio su vida. En este sentido, no sólo su filosofía sino también su praxis y su destino dan mucho que pensar y pueden ser también para todos una exhortación para actuar"7. No se trata aquí de seguir en detalle el reiterado y cuidadoso tratamiento que da a esta cuestión Samours. Lo que sí importa subrayar es el matiz de precisión que habría aportado Ellacuría, según muestra en su estudio. Matiz que considero ha sido muy poco atendido en la reflexión previa y posterior al asesinato del jesuita. Señala con fuerza Samour que, en la concepción de Ellacuría profundamente organizada a partir del magisterio de Xavier Zubiri, "... para hablar con rigor y seriedad de un futuro no es suficiente llamar así a todo lo que aún no es, aunque se tenga potencia física para realizarlo: sólo es futuro aquello que aún no es, pero para cuya realidad están actualmente en un presente dado todas sus posibilidades" . Aquí ya está, in nuce, la distinción capital entre potencia y posibilidad. La primera en sentido aristotélico y la segunda en versión zubiriano-ellacuriana. Samour subraya conclusivamente esta distinción al anotar que Ellacuría “... entiende la realidad histórica como apropiación y actualización de posibilidades y no como desarrollo en acto de lo que en potencia está ya dado al principio de la misma"10. Por ello la acción humana incluye el triple carácter de agente, actor y autor. Si se absolutiza de modo excluyente una de estas tres dimensiones en desmedro de las otras se desarticula y desfigura lo humano. Por ello precisa Samour "... si se exagera en forma absoluta el carácter de agente se cae en una visión naturalista [...] que reduce la vida humana a mero movimiento de potencias [...] si se absolutiza el carácter de actor se da lugar al escepticismo y a las diversas formas de fatalismo [...] Aquí se sitúa la pasividad de los oprimidos que toman lo dado como lo real [...] Finalmente, si se absolutiza el carácter de autor se cae en el idealismo de la libertad, por cuanto se dejan de lado los condicionamientos reales y materiales de su ejercicio..." ". Por ello puede consignarse como tesis fuerte la siguiente afirmación: “... la opción humana es opción absoluta en cuanto opción, pero no es absoluta en 
cuanto a los contenidos de esa opción, que son siempre contenidos muy determinados y en alguna medida determinantes de la acción humana. La opción no es sin más libertad absoluta; la opción humana es siempre entre posibilidades reales muy precisas"12. En una nota a pie de página queda condensada la aportación fundamental de Zubiri a esta concepción. Vale la pena traerla a cuento aquí tal cual la elabora Samour: "El hombre en virtud de su apertura no está "por-bajo-de" sus propiedades; sino que está "por-encima-de" ellas, puesto que se las apropia por opción. "En su virtud, yo diría que en este aspecto no es bypo-keimenon, sino más bien, byper-keimenon, algo no sólo sub-stante, sino también supra-stante"'13. La praxis de los individuos es, por lo tanto, opcional ${ }^{14}$. Es un "... hacer opcional de carácter cuasi-creador"15. Por ello insiste Samour e incluso cita expresamente a Ellacuría para confirmar que "... en la concepción ellacuriana el concepto que define primariamente lo histórico es el concepto de posibilidad o mejor de posibilidades: "Entendemos aquí por formalmente histórico aquello que pasa a ser actualmente real en virtud de una opción, sea ésta puesta por un sujeto individual para sí o para los otros, sea puesta por un sujeto social. Hay historia siempre que hay actualización de posibilidades -y no actualización de potenciasmediante una opción"'16. Valgan estas consideraciones iniciales para sugerir la fuerza de la argumentación de Ellacuría muy bien destacada y, si cabe, reforzada por la inteligente interpretación de Samour.

Sobre el punto acaba de insistir Pedro Casaldáliga en una "Carta abierta al Hermano Romero", a propósito de un aniversario más de su asesinato. "Contigo, decía el maestro mártir Ellacuría, "Dios ha pasado por El Salvador", por todo nuestro mundo. Y el teólogo de frontera José María Vigil ha hecho de ti tres rotundas afirmaciones que son, más que verdades para creer, desafíos de urgencia para asumir:

"Romero: símbolo máximo de la opción por los pobres y de la teología de la liberación.

Romero: símbolo máximo del conflicto de la opción por los pobres con el Estado.

Romero: símbolo máximo de la opción por los pobres con la Iglesia Institucional"1'.

Más adelante habrá que matizar, pero sirva por el momento para cerrar este apartado de fuerte tufillo teológico una afirmación de Moisés Fuentes en un artículo reciente: “... forjada en una tradición que considera los

Prellminares hacio una recuperoción del cuerpo en el pensamiento ketilnoomericano contemporáneo 
placeres eróticos -tanto en el aspecto sentimental cuanto el carnal- un pecado y que considera al cuerpo como origen de bajas pasiones y de perdición del espíritu, la religión cristiana ha debido eludir lo erótico en el libro que la fundamenta, la Biblia" ${ }^{m 18}$.

B) Los cuerpos que somos...

"Lo que hoy se sabe es que en el estado inicial de la pura materia había potencialidades efectivas que no se agotaban en la pura corporalidad ni en la forma de realidad que corresponde a la pura corporalidad ${ }^{\text {m19. }}$.

Uno de los primeros estudiosos en llamar la atención acerca de la importancia del cuerpo en la filosofía nuestroamericana ha sido Arturo Rico Bovio. En dos obras decisivas para el inicio de esta discusión desarrolló la tesis central de que no tenemos, sino que somos cuerpo. Su primer trabajo partió de una reconsideración de la obra clásica de Maurice Merleau Ponty, Fenomenología de la percepción. Rico Bovio la leyó desde nuestra situación cultural e histórico social y esto le permitió abrir una veta de investigación muy fecunda ${ }^{20}$. Más adelante, su peculiar enfoque cuajó en una obra muy bien lograda y de amplio espectro sobre el derecho desde una perspectiva corporal. Con un lenguaje tan riguroso cuanto accesible, construyó una filosofía del derecho a partir de una definición de cuerpo que merece considerarse en toda su fecundidad conceptual. Debajo de su aparente sencillez enunciativa, esconde una carga muy potente de sentidos. "Definiré "cuerpo", por tanto, como la totalidad articulada de un ser, en este caso el humano, en el conjunto de sus aspectos visibles e invisibles; perceptibles o únicamente inferibles por medios

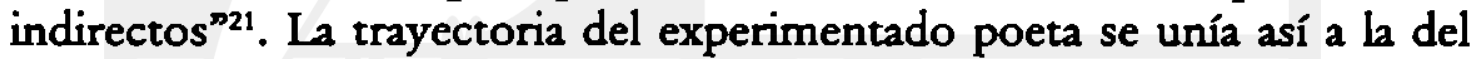
concienzudo filósofo para producir un enfoque que todavía no ha dado de sí todo lo que puede brindar. Rico Bovio trabaja ahora en el despliegue de estas potencialidades de su propuesta teórica.

Por su parte, en un trabajo reciente, Norma Durán ha comparado con fuerza y pertinencia las diferencias entre el dualismo occidental ( $y$ sus desventajas) frente a la concepción unitaria oriental. Lo cual permite avanzar hacia una tríada: razón, intuición, cuerpo y, sobre todo, hacia la perfección circular. La percepción aparece así reconceptualizada o vaciada en nuevos marcos de consideración o matrices significativas. Prioritaria pero no necesariamente enemistada con la razón, en la medida en que el cuerpo se constituye en el "lugar" donde ambas facultades se sintetizarian, 
al punto que no puede darse una sin la otra ${ }^{22}$. El recorrido, por así decirlo, de las energías cubren un círculo que metafóricamente (y quizá no tan metafóricamente) pasa por las siguientes etapas-símbolos-instancias: fuego, metal, madera, tierra, agua ${ }^{23}$. Durán trabaja ahora en las consecuencias de este giro en la concepción antropológica para la medicina ${ }^{24}$. Una muestra palpable de este respeto a los cuerpos que somos es la ayuda internacional de los médicos cubanos. Una parte de su trayectoria ha sido recogida con esmero en el diario de viaje de Enrique Ubieta, que se estructura como una reflexión profunda y responsable sobre nuestra historia y nuestros deberes actuales ${ }^{25}$. El caminar de estas brigadas médicas junto a los pueblos abre instancias de futuro soñado.

En el cuestionamiento radical de las exageradas ambiciones reduccionistas del pensamiento hegemónico pretendidamente único, María Arcelia González Butrón estriba en la dimensión corporal para reivindicar la satisfacción de necesidades siempre postergadas. Así, anota con toda elocuencia: "Es fundamental considerar la corporeidad como fuente de criterios para una ética solidaria, los cuerpos vivientes como fuente de criterios de verificación tienen que prevalecer para enfrentar una lógica de mercado totalizante y todas sus mediaciones"26. Echa de este modo las bases de una ética respetuosa de las necesidades de los cuerpos que somos, frente a una sociedad donde el consumismo hace perder de vista las necesidades básicas y, mucho más, las necesidades radicales. Una sociedad que no vacila en postular vigencia de derechos y en hacerse de la vista gorda frente a la trata (mercadeo de los cuerpos finalmente) y al tráfico de órganos (partes de cuerpos), particularmente de niños ${ }^{27}$.

Cuerpo somos no sólo individualmente sino colectivamente y esto conlleva una serie de consideraciones donde las dimensiones institucionales deben ser asumidas. Con todo, es siempre este cuerpo que soy el que padece o disfruta. Así lo ha mostrado el horror de la tortura como mecanismo central de la violencia estructural, del terrorismo de estado aplicado a mansalva durante períodos críticos de nuestra historia reciente y nunca abandonado como recurso de 'gobernabilidad'. Con el esfuerzo que ha significado transformar su experiencia personal en elaboración conceptual a la búsqueda de sentidos y sinsentidos de la acción colectiva, lo ha destacado a propósito de la represión en Argentina durante la llamada "guerra sucia", Pilar Calveiro. Sin cuerpo, no hay tortura... En su estudio apunta un dato, cuya importancia es imposible exagerar: la responsabilidad de lo ocurrido no fue sólo de los milicos, sus principales protagonistas.

Preliminares hacia una recuperactón del cuerpo en el pensomlento latinocmericano contemporáneo 
También la sociedad en su conjunto debe asumir la parte que le toca ${ }^{28}$. Lo cual previene contra apresuradas idealizaciones de la ahora denominada 'sociedad civil'.

Recientemente, en consonancia con sus estudios sobre comunicación, democracia y utopía en Nuestra América, Manuel Corral ha explorado la dimensión de la corporalidad En un trabajo inédito dirigido especialmente a los jóvenes, a partir de la convicción de que "La estructura del cuerpo humano está programada genéticamente para la comunicación", señala: "Ensayo sobre algunos elementos que podrían llamarse somatográficos; sólo los suficientes, para hablar de sensaciones perceptivas necesarias para una comunicación realmente humana, y para gozar y disfrutar la producción y la recepción del arte ${ }^{\mathbf{2 9}}$. Sobre esto se regodea el texto que esperemos se publique lo antes posible. Cuerpos somos y cuerpos comunicados o comunicables. En apertura hacia una interacción sin la cual la vida es sencillamente inviable ${ }^{30}$.

En esta vena de educación de la percepción artística, justamente por prestar atención a la corporalidad, me parece, el ya fallecido amigo uruguayo, don Roberto Ares Pons pudo visualizar y apreciar de modo muy sugerente y audaz la obra pictórica de un clásico. Donde otros sólo vieron el dolor provocado por la muerte, él supo ver la aparición de la vida en el parto y, por si fuera poco, sus repercusiones en la reivindicación de la carne, supuesta hasta de facto en la eucaristía para los católicos. La obra del Greco recobra así toda su sugerente y provocativa carnalidad para dejarnos, en líneas sin desperdicio, una hipótesis de trabajo ciertamente seductora: "Si los cuadros de los pintores que expresan esa vivencia religiosa, como los del Greco, presentan esa cualidad visceral y esas analogías orgánicas, es porque toda la religiosidad hispánica, y particularmente su vertiente mística, se distingue por su afán de envolver, en una misma y sola operación redentora, al espíritu y la carne ${ }^{\text {m11. }}$. Esta tesis de Ares Pons matiza, quizá por tomar en cuenta con más vigor la tradición iberoamericana, los señalamientos de Moisés Fuentes mencionados al final del primer apartado.

El cuerpo que somos es además de niño, joven, anciano, negro, indígena, mujer, etc. Cada uno de estos aspectos merecería tratamiento aparte $^{32}$. Pero, conviene quizá concentrarse en el caso del cuerpo sexuado para sugerir algunas líneas de reflexión fecunda. Con términos explícitos lo señala Francesca Gargallo en un texto decisivo para comprender el pensamiento feminista en Nuestra América: "para mí el caos es un hecho

Reolidad 105, 2005 
positivo, a la vez que inevitable. El caos, según Pitágoras, es la contraparte del cosmos, que no es sino caos delimitado, medido, arbitrariamente convertido en algo previsible; y se relaciona con la noche, con los números pares, con las mujeres. Cuando quiero pensar en algo que me agrada, pienso en la sangre menstrual que desordena hasta las dietas de los nutriólogos más estudiados, la noche que engendra, las-los hermafroditas que luchan para que los dejen mutilar convirtiéndolos a uno de los dos sexos socialmente reconocidos, la lava cuando baja sobre ciudades contaminadas y devuelve sus nutrientes a la tierra que quema, el movimiento feminista mientras dice a las diferentes culturas que apresan a las mujeres en sus sistemas de parentesco masculinos: "sus medidas y hasta su sistema de medición no nos sirven porque hemos aprendido a reconocernos unas a las otras". En otras palabras, pienso en algo caótico para el sistema taxonómico que sustenta las lógicas de dominio ${ }^{m 33}$. Sólo el desparpajo permite ir abriendo grietas, con grandes dificultades, en un ejercicio de lenguaje acostumbrado a la inercia machista y patriarcal ${ }^{34}$. Y después añadía, recordando a la cubana Aralia López González, que “... el feminismo no es un discurso hegemónico, pues tiene tantas corrientes como las que pueden surgir de las experiencias de los cuerpos sexuados

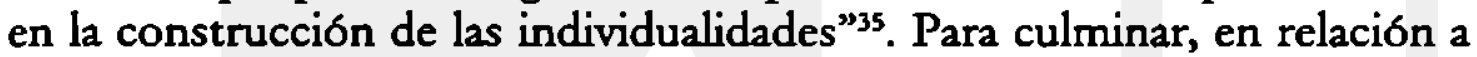
lo que venimos esbozando en este trabajo, señalando que "... a mediados del siglo XX, las escritoras latinoamericanas empezaron a manifestar masivamente que su escritura estaba determinada por su cuerpo y por el lugar que éste tenía en las historias familiar, nacional y continental ${ }^{36}$. Esta referencia a la literatura abre también un campo de exploración riquísimo. Sólo quisiera acotar aquí un ejemplo de literatura escrita por varón, pero desde la corporalidad agraria mexicana justamente de mediados del siglo XX. En los cuentos reunidos bajo el título de Céfero, Xavier Vargas Pardo ilustró a inicios de los años sesenta el lenguaje transido de corporalidad del campesino mexicano. Al punto que quizá no habría cuento ni lenguaje sin esas reiteradas referencias corporales casi obsesivas, aunque por demás elocuentes ${ }^{37}$.

Metidos a la literatura es irresistible la referencia al estupendo estudio que sobre la obra de Corín Tellado produjo María Teresa González García. Es su esclarecedor prólogo, Gustavo Bueno destacó, con su perspicacia y rigor habituales, que "la perspectiva de Corín Tellado no es, según esto, estrictamente naturalista, pero tampoco es la perspectiva del realismo fantástico, puesto que las normas éticas y morales no son simples ilusiones, sino componentes efectivos, y aun etológicos, de las conductas de los

469

Preliminares hacla una recuperaction del cuerpo en el pensam'ento latinocmericano contemporineo 
sujetos de una especie determinada" ${ }^{38}$. Y es que Bueno trabaja con nociones bien precisas de ética y moral, según hace explícito a sus lectores. "En ocasiones las normas éticas y las normas morales son incompatibles y entran en conflicto: las normas éticas son aquellas que están talladas a escala de sujetos corpóreos individuales (ethos = carácter individual), mientras que las normas morales (mores $=$ costumbres) son aquellas que están talladas a escala de los sujetos operatorios en tanto son miembros de un grupo (una horda, una banda, una familia, una clase social). El principio de las normas éticas es el principio de la preservación de la vida corpórea de los individuos en cuanto tales (no sólo del ego): el delito ético supremo es quitar la vida a otro o a uno mismo. El principio de las normas morales es el de la preservación de la existencia del grupo como tal; y este principio moral conduce muchas veces a violentar la norma ética fundamental, a saber, siempre que la moral del grupo requiera el sacrificio de las inclinaciones o incluso de la vida del sujeto corpóreo (pulchrum est pro patria mori)"39.

A la búsqueda de la constitución de la subjetividad que hará posible el capitalismo y su lógica de la muerte, León Rozitchner remonta la cuestión hasta el cristianismo de Agustín. "Creemos que el cristianismo, con su desprecio radical por el goce sensible de la vida, es la premisa del capitalismo, sin el cual éste no hubiera existido. Puesto que para que haya un sistema donde paulatinamente todas las cualidades humanas, hasta las más personalizadas, adquieran un precio -valor cuantitativo como "mercancía", forma generalizada en la valoración de lo existente- fue necesario producir primero hombres adecuados al sistema en un nivel diferente al de la mera economía"40. Por ello, señala que "Se requirió primero que el cuerpo de la madre genitora, con cuya imagen cada hombre anima aún el suyo, fuera excluido en la Virgen como cuerpo de vida. Esta negación tuvo que penetrar, para ser eficaz, hasta lo inconsciente. Por eso el cuerpo de la madre virgen es la primera máquina social abstracta productora de cuerpos convocados para la muerte [...] En su economía libidinal teológica el santo nos proponía, desde muy antiguo, la inversión originaria más rendidora para acumular capital sagrado: "mediante el aborro en carne podréis invertir en Espiritu"'11. El cristianismo aparece así radicalizado en relación a sus antecedentes semitas. "Y la nueva exigencia es sólo una, que anulemos todo goce del cuerpo..."12. La figura incestuosa de Agustín resulta así plenamente significativa de ese hombre que se amputa de los placeres y que servirá de base a un capitalismo anti vida. "La decisión fundamental del "ser o no ser" espiritual del cristiano Agustín 
se reduce al problema de fornicar o no fornicar. No es una alegoría ni un símbolo; se trata de la realidad más inmediata, simple y corporal de los órganos sexuales, las posturas de los cuerpos, los declives sinuosos de las curvas, la visibilidad de los húmedos agujeros entreabiertos que desafían y hacen guiños al deseo, y el deslizar secreto y silencioso de los untuosos fluidos seminales y vaginales -y quizá también de los anales"43. $Y$, sin embargo, la premisa siempre permanece clara, incluso para Agustín: “... el pensamiento que no surge del cuerpo no puede ser soporte de la vida; para soportar una vida siempre se necesita cuerpo"'44.

Pero, sería un teólogo protestante brasileño quien llevara la cuestión a límites insospechados. Y es que ya en los ochenta, Rubem Alves, uno de los fundadores de la teología de la liberación, meditaba en la encarnación, en el alimento corporal para el cuerpo (forma de antropofagia ritual) y, sobre todo, en la clave de la fe cristiana: la creencia en la resurrección de los cuerpos, de los cuerpos de cada uno, del cuerpo que soy's. Aquí es donde la fe se ponía de verdad a prueba y donde se alcanzaba a visualizar hasta dónde llegaría la promesa divina. En un estudio cuidadoso y sugerente, Leopoldo Cervantes-Ortiz ha hurgado por numerosos ángulos del enfoque de Alves. Vale la pena recordar aquí un pequeño fragmento de la teopoética de Alves reproducido en el indispensable estudio ya mencionado. "Una cuestión que posteriormente se quedó, o tomó muy importante para mí es la cuestión del cuerpo. Comprendí, que todas la luchas que se hacen tiene la única finalidad de hacer que el cuerpo sea feliz.

No hay absolutamente nada en el mundo más importante que el cuerpo. Si nosotros hacemos la revolución, la única finalidad de la revolución es permitir que los cuerpos no tengan dolor, que los cuerpos no tengan miedo, que puedan dormir en paz, que puedan trabajar en paz, que puedan crear el amor, que puedan tener sus hijos. Que puedan vivir el futuro sin temores, sin angustias.

Entonces, mi pensamiento sobre Dios se transformó realmente en un pensamiento sobre la liberación del cuerpo. Además, para los cristianos, el más alto símbolo religioso que existe es el símbolo de la resurrección del cuerpo. Resurrección del cuerpo significa por lo menos dos cosas, libertad, dignidad. Son para mí los dos más altos valores de la religión cristiana" ${ }^{\text {"46. }}$.

Más recientemente, tres jóvenes profesores del Centro de Estudios Filosóficos y Teológicos de los Claretianos en Córdoba, Argentina, han

Prellninares hacia una recuperactón del cuerpo en el penscriento latinocmericano contemporíneo 
radicalizado la cuestión. El cuerpo aparece concebido como propiedad privada. El sistema fomenta, así, una seducción opresiva, que actúa por miedo y procura cooptar la fuente de todo poder: el deseo. El cuerpo es límite y posibilidad del poder y sólo se lo puede rebasar por donación. Pero, para la lógica dominante en el sistema capitalista el don alucinado es la propiedad. Por eso, cuando “... los lobos tiene miedo por sus propiedades reclaman ética"47. Con lucidez crítica estos tres colegas reclaman una política no eticista y, más bien, esteticista. Que haga posible el goce, el placer, la donación y la plenitud de lo corporal humano; la recuperación, en suma, de la sensibilidad ${ }^{48}$.

Como anticipa el epígrafe de esta sección hay que tener cuidado. La corporalidad no agota la materia. Aunque, parece quedar claro, que sin pasar por ella, no hay materia que valga. Frei Betto, en un texto pleno de erudición científica, invita a transitar las "veredas que conducen de las estrellas a la subjetividad"'99. Quizá por eso se atreve a introducir el amor en la física. Y no en sentido metafórico, sino aparentemente literal. "De cierto modo, lo que sustenta al átomo es una cuestión de amor [...] Como los amantes, los átomos sólo se unen cuando están excitados, ya sea porque se calienten o porque alguna otra sustancia química atrae a uno de ellos. Al ser absorbidos por los átomos, la energía del calor de la excitación modifica la corona de electrones que rodea al núcleo y propicia la unión de dos átomos, que forman una molécula. iUna gravidez en plena luna de miel!"50. La vida, entonces, se perfeccionaría mediante asociación de niveles que después nos hemos empeñado en disociar con dualismos aberrantes. "Cuando la vida se perfeccionó, hace 200 millones de años, la estructura biológica asoció sexo y ternura, y celebró, con los primeros mamíferos, el surgimiento de la educación" $"$. La insinuación es clara. Quizá tenemos todavía tiempo de educarnos para llegar a ser lo que somos en plenitud.

En un texto finamente sugestivo Hugo Aréchiga supo poner al alcance de un amplio público interesado ciertas claves de la vida. Una vida que no puede entenderse sin ciertos equilibrios. "Esta tendencia al equilibrio llevó a Claude Bernard (1813-1878) a afirmar que "la constancia del medio interno es la condición de la vida libre e independiente" [...] El conjunto de acciones fisiológicas que llevan al mantenimiento de la constancia propuesta por Bernard fue caracterizado por Walter Cannon (1871-1945), en 1926, como homeostasis" 52 . Por extensión, el término homeostasis ha tenido fortuna en diferentes niveles de análisis: físico, químico y social, 
como lo señalara el mismo Aréchiga ${ }^{53}$. Ahora bien, como esa pretendida "constancia" de las funciones corporales ha sido cuestionada "Se ha llegado entonces a proponer la sustitución del término homeostasis por el de "homeorresis", en alusión a que la constante es el cambio, el flujo de energía y de materia. Es ahora reconocido que nuestras funciones biológicas, lejos de permanecer constantes a lo largo de toda la vida, manifiestan espontáneamente grandes modificaciones..." "st. No es del caso entrar en este momento a otros detalles, pero sí conviene anotar que esa noción de "constancia" hacía parte de un cierto paradigma que incluía también, por un lado "Dos acontecimientos resonantes de la medicina experimental durante el siglo pasado [como] fueron el descubrimiento de la inmunidad, que llevó a la producción de vacunas y antitoxinas, y el de la fagocitosis, que puso de manifiesto la existencia de células especializadas en la destrucción de células extrañas o la inactivación de moléculas ajenas. Algunas de las células del sistema inmune, como son los glóbulos blancos, actúan en la circulación sanguínea"ss. Con lo cual podemos relacionar el segundo y muy importante aspecto, que viene a confirmar lo que anotamos a propósito de la comunicación. "Con el tiempo se ha establecido que a través de la sangre cada célula del cuerpo puede estar en comunicación con todas las demás"56. A todos los niveles es válida entonces la afirmación de que "La vida es un proceso continuo

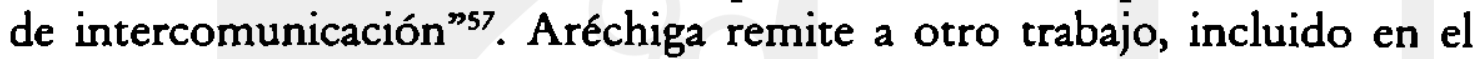
mismo volumen colectivo, que complementa y completa de manera muy pertinente su aporte. En él, Marcelino Cereijido muestra el modo en que la muerte ha pasado a ser concebida como parte de la vida, mediante el examen de la apoptosis o muerte genéticamente programada. Lo cual le permite sugerir las ventajas de la muerte. Por ello concluye de manera contundente: "Es obvio entonces que hasta hace apenas veinte años, la muerte era un suceso "extravital", en el sentido de que venía a interrumpir una vida que se consideraba potencialmente eterna y de la que no formaba parte. Por el contrario, hoy la ciencia muestra que se trata de un mecanismo fundamental de la vida, impreso en lo más íntimo de nuestros genes, sin el cual la evolución no hubiera llegado a producir a los humanos, ni nuestros organismos estarían correctamente desarrollados y tampoco tendríamos cultura" ${ }^{38}$. Esta contundencia está basada, como el mismo Cereijido lo anota, en la noción de apoptosis. Y sobre ella precisa con todo cuidado: "La apoptosis no es un desordenado descalabro celular, sino por el contrario se trata de un cuidadoso desensamble de estructuras, trozado de enzimas, liberación de sustancias, con lo cual la célula se va 
autoeliminando. Los genes apópticos que provocan esos cambios se expresan secuencialmente, $y$ en sus últimos pasos instruyen incluso la formación de substancias que atraen a los macrófagos y provocan que éstos las devoren y no quede ningún resto de la célula suicida. Por supuesto, estos pasos son tan numerosos, complejos y delicados, que pueden fallar, por lo que se estima que hay toda una frondosa patología, debida a esa falta de una muerte que debería haber ocurrido, o que ocurrió a destiempo, que todavía está por estudiarse, y que sin duda aclarará el mecanismo de muchas enfermedades ya conocidas pero cuya causa aún se ignora.

Hoy el arsenal experimental de la biología tiene técnicas que permiten silenciar específicamente un gen determinado. Cuando anula la función de un gen de la muerte celular programada, no consigue la vida eterna, sino que provoca la aparición de tumores y monstruosidades. De modo que, como conclusión de este punto, podemos afirmar que la muerte celular programada es un mecanismo fundamental, gracias al cual los organismos se construyen correctamente ${ }^{n 59}$.

\section{A modo de epílogo insuficiente...}

"En ese ti[em]po tuve la comprobación de algo que ya había" observado antes. A la inversa de lo que ocurre con el trabajo meramente físico, el trabajo donde entra en acción el espíritu; resulta más fácil, ligero y liviano a medida que uno va aumentando las horas de labor. Dijérase que el espíritu rinde más y con menor esfuerzo cuando más se le exige. Más aún; parecería que fuera necesario castigar y fatigar al cuerpo para que el alma eche el resto de su potencia creadora. Entonces me convencí de que el peor enemigo de todo creador es la molicie ${ }^{\text {60 }}$

Sólo he podido, malamente, invitar a algunas lecturas y compartir reflexiones surgidas de ellas. Me queda para mí que tomar en serio el cuerpo que somos exige replantearnos el sentido de la razón, de la ética y de la política. Pero, siempre, con una prioritaria preocupación epistemológica indeclinable. No trato de concluir nada. Más bien, insisto en insinuar algunas vías de indagación disponibles.

Este talante está impreso en uno de los mejores libros de filosofía con humor -como reza su epígrafe tomado de Epicuro: "Es preciso reír y, al mismo tiempo, filosofar"- que haya leído ${ }^{61}$. En él señala Ricardo Maliandi: 
"No: la Gran Pregunta no es la pregunta "¿qué hacer?", aunque sea el mismo Zeus quien la plantea. No es (o, para ser más exactos, no es meramente) la pregunta ética. Pero tampoco es la pregunta metafísica (aquella de "ipor qué es el ente y no más bien la nada?"). La Gran Pregunta tiene que contener todas las preguntas filosóficas; pero también tiene que contener nuestros desvelos por nuestra muerte individual y por la posible extinción de la especie humana. Tiene que ser una pregunta apocalíptica: la pregunta que haríamos si estuviéramos ya en los segundos finales, antes de que el mundo se vaya totalmente a la mierda, la pregunta que podrían plantearse los que no se hubiesen horrorizado por usar la palabra "mierda" en este contexto"62.

Queda así abierto, desde el lenguaje mismo, el inmenso ámbito de la transgresión en tanto correlato de la prohibición. Y se impone el retorno a la reflexión clásica de Georges Bataille (1897-1962) en El erotismo. En esa obra, escrita durante la segunda guerra y 1957, Bataille desarrolló brillantemente la dialéctica entre prohibición y transgresión. Aún siendo todas atingentes e nuestro tema, no me resisto a reproducir algunas de sus brillantes líneas; las más provocativas para suspender de momento este itinerario. "Lo que el acto de amor y el sacrificio revelan es la carne. El sacrificio sustituye la vida ordenada del animal por la convulsión ciega de los órganos. Lo mismo sucede con la convulsión erótica: libera unos órganos pletóricos cuyos juegos se realizan a ciegas, más allá de la voluntad reflexiva de los amantes. A esa voluntad reflexiva la suceden los movimientos animales de esos órganos hinchados de sangre. Una violencia, que la razón deja de controlar, anima a esos órganos, los hace tender al estallido y súbitamente estalla la alegría de los corazones al dejase llevar por el rebasamiento de esa tormenta. El movimiento de la carne excede un límite en ausencia de la voluntad. La came es en nosotros ese exceso que se opone a la ley de la decencia. La carne es el enemigo nato de aquellos a quienes atormenta la prohibición del cristianismo; pero si, como creo, existe una prohibición vaga y global que se opone, bajo formas que dependen del tiempo y del lugar, a la libertad sexual, entonces la carne es la expresión de un retorno de esa libertad amenazante ${ }^{n 63}$.

El enfoque dialéctico se renueva y reitera a lo largo de la reflexión de modo sugerente. "En general no acabamos de comprender el carácter erótico, o más simplemente transgresor, del matrimonio, porque la palabra matrimonio designa a la vez el paso y el estado. Solemos olvidar el tránsito para considerar solamente el estado [...] Lo más grave es que el hábito 
suele apagar la intensidad y que matrimonio implica costumbre [...] Pero tampoco hay que descuidar la expansión de la vida sexual. Sin una secreta comprensión de los cuerpos, que sólo a la larga se establece, la unión es furtiva y superficial, no puede organizarse, su movimiento es casi animal, demasiado rápido, y el placer esperado suele hacerse esquivo. No hay duda que el gusto por el cambio es enfermizo y que sólo conduce a la frustración renovada. El hábito, por el contrario, tiene el poder de profundizar lo que la impaciencia no reconoce"64.

A propósito de su crítica cuidadosamente matizada al cristianismo, Bataille señalaba al trabajo como condición de la transgresión, con lo cual quedamos de nuevo remitidos a la cotidianidad de nuestra situación histórica actual en toda su acuciante y angustiosa carencia de rumbos. Y es que quizá ni siquiera quede espacio para el desorden... "Por el hecho de que comporta el rebasamiento hacia un mundo organizado, la transgresión es el principio de un desorden organizado. De la organización, a la cual habían accedido los que la practican, le viene su carácter organizado. Esta organización, fundada en el trabajo, se fundamenta a la vez en la discontinuidad del ser. El mundo organizado del trabajo y el mundo de la discontinuidad son un solo y único mundo"65.

\section{Santa Úrsula Xitla, Tlalpan, 20 de abril de 200:}

Notas

1 Ernesto Mejía Sánchez, “La carne contigua” de 1948 en: Recolección a mediodía. Presentación de Alfonso D'Aquino. México, Consejo Nacional para la Cultura y las Artes, 1995, pp. 44-45.

2 Cf. Hugo Assmann, Teología desde la praxis de la liberación; Ensayo teológico desde la América dependiente. Salamanca, Sígueme, 1973. Para un examen más pormenorizado de sus propuestas en relación con estos aspectos remito a mi Filosofía de la liberación latinoamericana. México, FCE, 1983, pp. 128-134.

3 Gustavo Gutiérrez, "Pobres y opción fundamental" en: Ignacio Ellacuría y Jon Sobrino (coordinadores), Mysterium Liberationis. Conceptos fundamentales de la teología de la liberación. San Salvador, UCA Editores, T. I, 1993, p.309.

1 Ignacio Ellacuría, "Utopía y profetismo" en: Mysterium Liberationis, p. 401.

s Para una orientación preliminar sobre el tema remito a algunos de mis trabajos: De varia utópica (Ensayos de utopía III). Bogotá, Universidad Central, 1989, 239 págs.; Presagio y tópica del descubrimiento. México, UNAM, 1991, 156 págs.; "¿Teoría de la utopía?" en: Oscar Agüero y Horacio Cerutti Guldberg (editores), Utopía y Nuestra América. Quito, Abya-Yala, 1996, Pp. 93-108. 
Por ejemplo, Juan Carlos Scannone escribía: “En una concepción marxista a las clases sociales intermedias no proletarias a lo más les compete un papel meramente auxiliar en el proceso de liberación. De la dialéctica que esbozamos [analéctica] se concluirá el papel ético que en él les roca a dichos grupos sociales (no decimos clases), pues, como son grupos solicitados por las ventajas del sistema, su opción libre por los oprimidos es un gesto moral altamente significativo del hombre nuevo que se pretende instaurar. Para la liberación no basta que se den las condiciones objetivas, sino que también son necesarias las subjetivas" ("La liberación latinoamericana. Ontología del proceso auténticamente liberador" en: Stromata. Buenos Aires, año XXVIII, enero-junio 1972, números 1-2, p. 133, nota 20). Para un tratamiento más detallado de este punto remito a mi Filosofía de la liberación..., pp. 258-259.

7. Héctor Samour, Voluntad de liberación. El pensamiento filosófico de Ignacio Ellacuria. San Salvador, UCA Editores, 2002, p. 395. Por supuesto, no conviene extralimitar el alcance de la afirmación sobre la no "posibilitación", porque quizá sería contradictorio con todo el planteamiento de esta importante obra. Lo que interesa es lo decisivo de la opción que Ellacuría adoptó.

- Prácticamente todo su texto está dedicado de facto a examinar el asunto. Lo cual me hace insistir, con Samour, en la idea de que fue un leit motiv fundamental de la vida de Ellacuría. Con todo, no está demás citar algunos de los lugares donde el tratamiento es explícito. Cf. por ejemplo, pp. 23, 68, 73, 75, 77, 85, 90, 92, 99, 101, $102-103,112,116,143,149,162,168,204-205,229,239,284,287,299,302,304$, $320,330-331,336,365,387$.

Op. cit., p. 75.

Ibídem, p. 204.

"Ibídem, pp. 77-78 (los subrayados son míos).

12 Ibídem, p. 90.

13 Ibídem, p. 143, nota 243. Samour indica la referencia a la cita de Xavier Zubiri, Sobre el hombre. Madrid, Alianza Editorial-Sociedad de Estudios y Publicaciones, 1986, p. 343.

14 Cf. ibídem, p. 149.

$15 \quad$ Ibídem, p. 162.

16 Ibídem, p. 330. El subrayado es de Samour.

17 En ALAI-AMLATINA. 31/o3/2005. Conviene recordarlo ahora más que nunca en tiempos ya de Benedicto XVI.

18 Moisés Elías Fuentes Aburto, “"Thamar y Amnón” y "La carne contigua": imaginerías de un tema bíblico" en: Cuadernos Americanos. México, UNAM, Nueva Época, año XLX, vol. 1, enero-febrero 2005, $n^{\circ} 109$, p. 95. La lectura de este trabajo me llevó al poema de Mejía Sánchez, del cual seleccioné el fragmento que figura como epígrafe de este apartado.

19 Héctor Samour, Voluntad de liberación..., pp. 136-137.

20 Arturo Rico Bovio, Las fronteras del cuerpo. Crítica de la corporeidad. México, Joaquín Mortiz, 1990, 175 págs. No deja de sorprender, por eso mismo, que se 
aventuren trabajos sobre el mismo campo de reflexión, muchos años después y sin hacer ninguna referencia a sus trabajos, cuando releídos retrospectivamente se aprecia el inmenso aporte que efectuó. Cf., por ejemplo, el artículo de Ma. Carmen López Sáenz, "Intersubjetividad como intercorporeidad" en: La Lámpara de Diógenes. Puebla, BUAP, año 5, enero-junio2004/julio-diciembre 2004, nos. 8 y 9, Vol. 5, Pp. 57-70.-

21 Teoría corporal del derecho. México, Miguel Ángel Porrúa/Facultad de Derecho, Universidad Autónoma de Chihuahua, 2000, p. 80.

22 Norma Delia Durán Amavizca, Cuerpo, intuición y razón. México, CEAPAC ediciones, 2004, 142 pags.

23 En una de sus enunciaciones se expresa así: “... el fuego funde al metal; el metal corta la madera; la madera penetra la tierra; la tierra absorbe el agua y, por último, el agua apaga el fuego" (Ibídem, p. 93).

24 La preocupación por la salud del colectivo es extendida. Cf., por ejemplo, Ineida Machado, "Bioética y biopolítica: una complementariedad filosófica necesaria en el derecho a la no exclusión" en: Cuadernos de Filosofía Política, Ética y Pensamiento Filosofico Latinoamericano. Mérida, Universidad de Los Andes, 1999, pp. 153-160. No es un dato menor que la Revolución Bolivariana de Venezuela tenga como punta de lanza la salud de la población.-

25 Enrique Ubieta Gómez, La utopía rearmada. Historias de un viaje al nuevo mundo. Colombia/La Habana, Casa Editorial Abril, 2002, 379 págs.

26 El llamado desde la corporeidad del sujeto en tiempos de neoliberalismo. Hilvanando reflexiones desde la economía, la ética y el feminismo" en: Desde los cuerpos. De la crítica a la economía de mercado y las políticas neoliberales a las propuestas. México, SEMIF, EMAS, UMSNH, 2002, p. 58.

27 Al tiempo de dar toque final a este trabajo, José Carlos García Ramírez tuvo la gentileza de facilitarme su trabajo Corporalidad y derechos humanos en Karl Marx (1835-1858). México, FFYL (UNAM), Tesis para Licenciatura en Filosofía, 1995, 126 págs.

28 Pilar Calveiro, Desapariciones. Memoria y desmemonia de los campos de concentración argentinos. México, Taurus/La Huella del Otro, 2002 (la 1ed. es de 2001), 279 págs.

29 Cuerpo, comunicación y arte. México, agosto 2003, texto inédito al cual accedí por gentileza del autor.

30 En esta vena artística conviene tomar en consideración la escultura "corporal" (me parece atinente el término) del costarricense Jorge Jiménez Deredia. Cf. Geppe Inserra entrevista Jiménez Deredia, Génesis puente de luz. Pisa, Italia, Bandecchi \& Vivaldi, 2004, 132 págs. La edición ilustrada es bellísima. Debo el acceso a este texto que conviene discutir en detalle en otro lugar, a Tatiana Serrano. También puede estar pletórica de corporalidad la pintura, como lo muestra en magnífica edición Francesca Gargallo, Entraña de volcán. Pigmento y experimentación en Carlos Gutiérrez Angulo. Toluca, Instituto Mexiquense de Cultura, 2004, 107 págs. Agradezco a la autora el acceso al texto.

31 Roberto Ares Pons, "El enterramiento del Conde de Orgaz; Un parto" en: La Senda del Bubonero y otros ensayos. Montevideo, edición del autor, 2000, pp. 51-52. En este texto reunió sus trabajos como redactor en la Gaceta de la UNAM durante sus años de exalio en Méxaco. iCómo no recordarlo ahora que Unuguay transita una senda más esperanzadora y que tanto lo hubiera alegrado! 
Por ejemplo, el del texto ya clásico de Alfredo López Austin, Cuerpo humano e ideología Las concepciones de los antiguos nahuas. México, UNAM, 3 ed., 1989 (la primera es de 1980), T. I, 490 págs. Y T. II, 334 págs.

33 Francesca Gargallo, Las ideas feministas latinoamericanas. México, Universidad de la Ciudad de México, 2004, p. 19.

34 Cf. de Mauricio Gaborit, "El género pesa más que una arroba" en: José Joel Vázquez Ortega (coordinador), Psicología social y liberación en América Latina. México, UAM-I, 2000, pp. 247-257.

$35 \quad$ Ibídem, p. 46.

36 Ibídem, p. 130.

3) Xavier Vargas Pardo, Céfero, Cuentos. México, Editorial Los Reyes, $2^{2}$ ed. (la $1^{2}$ es del FCE en 1961), 2002, 149 págs. Para ilustración de quien lee, anoto algunos ejemplos léxicos incomprensibles sin la referencia al cuerpo en la cotidianidad, tomados sólo del primero de los cuentos: "buenisano", "muino", "i... le jinco un cabronazo a éste!", "con la lengua de pechera", "zambuto", "bolsiarme", "la sangre me gorgoreaba en el gaznate", "entumieron", "me fui de puro hocico", "amonaba", "cariao pa'l cielo", "hormigueo", "cuate... uña y carne", "trompiza", "apachurrado", "engarruñado", "trabao", "chupaleta", "parpariada", "ombligo pegado al espinazo", "destrabarme las quijadas", "despencando el brazo de la paleta", "chorriados y encueraditos, estilando lágrimas y mocos de tan escaldados", "patas pa'rriba", "güesitos", "ventiar", "meniao", "salivazo", "tronidos", "entelerido", "estaba como los músicos de rancho, que nomás en miar y afinar el instrumento se la pasan todo el día", "mejoradito", "jinco".

38 Gustavo Bueno, "Prólogo". Las "novelas de amor" de Corín Tellado desde la dialéctica ética-moral" en: María Teresa González, Corín Tellado, medio siglo de novela de amor (1946-1996). Oviedo, Pentalfa Ediciones, 1998, p. 20. Agradezco a Gustavo Bueno Sánchez el acceso a este trabajo.-

39 Ibidem, P. 19 (los subrayados son del original).-

10 León Rozitchner, La Cosa y la Cruz. Cristianismo y Capitalismo (En tomo a las Confesiones de san Agustin). Buenos Aires, Losada, 1997, p. 10.-

"Ibídem, p. 12.-

12 Ibídem, p. 204.-

43 Ibídem, p. 290.-

$4 \quad$ Ibídem, p. 192 .

15 Rubem Alves, Creio na resurreçâo do corpo. Meditaçôes. Rio de Janeiro, CEDI, 1982, 73 págs.

46 Cit. de una entrevista editada en México en 1984 por Leopoldo Cervantes-Ortiz, La teología ludo-erótico-poética de Rubem Alves. Quito, Centro Basilea de Investigación y Apoyo, 2003, p. 168. Carlos Mondragón ha tenido la gentileza de poner a mi alcance tanto este texto como el anteriormente citado de Alves.

17 Carlos Asselborn, Oscar Pacheco y Gustavo Cruz, "Proyecto de investigación: corporalidad y liberación latinoamericana". Córdoba, 2005. He accedido al texto inédito por gentileza de los autores.

t3 Aquí se impone enfrentar el sacrificio estéril. Examiné el problema a propósito de la poesía guerrillera en la región hace años. Remito a mi “El discurso político

Preliminares hacla una recuperaclón del cuerpo en el pensamtento latinoamericeno contempordineo 
centroamericano" en: De Varia Utópica (Ensayos de Utopía III). Bogotá, Universidad Central, 1989, pp. 91-119. Para el tema del sacrificio y sus consecuencias en el corporativismo mexicano (extensible, mutatis mutandi, en buena medida a toda la región latinoamericana) cf. de Marialba Pastor, Cuerpos sociales, cuerpos sacrificiales. México, FCE / FFYL (UNAM), 2004, 303 págs.

Frei Betto, La obra del artista. Una visión holística del universo. Valladolid, Trotta, 1999 , p. 42.

Ibidem, p. 126.

Ibidem, p. 179.-

Hugo Aréchiga, "Ciencias de la vida: el nivel individual" en: Pablo Rudomín y Norma Blázquez Graf (coordinadores), Ciencias de la Vida. México, CEIICHUNAM / Siglo XXI, 2001, p. 43. Sirva la ocasión para rendir merecido homenaje al colega prematuramente desaparecido y con el cual compartimos sugerentes sesiones en la Comisión Dictaminadora del CEIICH.

Cf. ibidem, p. 47.

Ibídem, p. 46.

Ibídem, p. 39. Por gentileza de Manuel Santos he sabido acerca de las obras del italiano Roberto Esposito. Particularmente, Immunitas. Protección y negación de la vida de 2002. No he podido leer todavía el texto, pero está en directa relación con este aspecto.

Ibídem, p. 51.

Ibídem, p. 53.

Marcelino Cereijido, "Muerte y vida" en: Pablo Rudomín y Norma Blázquez Graf (coordinadores), Ciencias de la Vida..., p. 130 (el subrayado es del original). No es del caso entrar aquí en la discriminación entre civilización y cultura, pero el autor había afirmado en la misma página unas líneas más arriba: “... una de las ventajas más evidentes que ofrece la muerte es haber provocado la civilización del ser humano".

Ibídem, p. 119.

Andrés Muñoz, Vida de Quinquela Martín. Edición abreviada compuesta la "Vida Novelesca de Quinquela Martín", escrita por Andrés Muñoz. Buenos Aires, [s.e.], 5 ed., 1971, p. 78. Agradezco a Néstor Medina el acceso a este texto.

1 Ricardo Maliandi, 16 jueces y 1 ahorcado. Con ilustraciones del autor. Mar del Plata, Argentina, Ediciones Suárez, 2003, 105 págs.-

Ibídem, pp. 100-101.

Georges Bataille, El erotismo. Barcelona, Tusquets, $3^{2}$ ed. en colección Ensayos ( $1^{2}$ en Les Éditions de Minuit, 1957), 2002, p.p. $97-98$ (Los subrayados son del original).

Ibídem, p. 157 (subrayados del original).

Ibídem, p. 125. 